Atıf için / For Citation: H. Arslan, "Prediction of excess molar volumes for quaternary liquid mixtures at 298.15 K", Süleyman Demirel Üniversitesi Fen Edebiyat Fakültesi Fen Dergisi, 16(1), 96-106, 2021.

\title{
Prediction of Excess Molar Volumes for Quaternary Liquid Mixtures at 298.15 K
}

\author{
Hüseyin ARSLAN ${ }^{* 1}$ \\ ${ }^{1}$ Kahramanmaras Sütçüimam University, Science Faculty, Physics Department, 46100, Onikisubat / \\ Kahramanmaras, Turkey \\ *corresponding author e-mail: arslan@ksu.edu.tr
}

(Alınış / Received: 03.02.2021, Kabul / Accepted: 10.03.2021, Yayımlanma / Published: 27.05.2021)

\begin{abstract}
The excess molar volumes for the ternary n-hexanol + ethanenitrile + dichloromethane and quaternary system n-hexanol + ethanenitrile + dichloromethane + tetrahydrofuran at $298.15 \mathrm{~K}$ has been calculated by using symmetric and asymmetric models. Chou's General solution model has been employed to evaluate the excess molar volume of the ternary n-hexanol + ethanenitrile + dichloromethane and quaternary systems in the n-hexanol + ethanenitrile + dichloromethane + tetrahydrofuran. The good agreement between experimental data and calculated results of excess molar volumes for both mixture systems indicates that this approach can be successfully used to predict the excess molar volumes of multicomponent systems.
\end{abstract}

Key words: Excess molar volumes, Redlich-Kister polynomial, General solution model, Quaternary systems.

\section{8,15 K de Dörtlü Sıvı Karışımların Fazla Molar Hacimlerinin Tahmini}

Özet: 298.15 K'de üçlü n-hekzanol + etanitril + diklorometan ve dörtlü sistem n-hekzanol + etanitril + diklorometan + tetrahidrofuran için fazla molar hacimler simetrik ve asimetrik modeller kullanılarak hesaplanmıştır. Chou'nun Genel çözüm modeli, n-heksanol + etanitril + diklorometan + tetrahidrofuranda üçlü n-hekzanol + etanitril + diklorometan ve dörtlü sistemlerin fazla molar hacmini değerlendirmek için kullanılmıştır. Her iki karışım sistemi için deneysel veriler ve fazla molar hacimlerin hesaplanan sonuçları arasındaki iyi uyum, bu yaklaşımın çok bileşenli sistemlerin fazla molar hacimlerini tahmin etmek için başarıyla kullanılabileceğini gösterir.

Anahtar kelimeler: Fazla molar hacim, Redlich-Kister poinomu, Genel çözüm modeli, Dörtlü sistem.

\section{Introduction}

From a scientific and technical point of view, multicomponent structures are of interest. It is well known that it is costly and time consuming to experimentally evaluate the excess functions of multicomponent structures. In addition, with the number of materials, the experimental problems increase dramatically. As a result, several papers on the prediction of physicochemical properties such as molar volume, molar enthalpy, density, viscosity and refractive indices have been published in recent decades [1-9]. In this paper, the excess molar volume of quaternary system n-hexanol + ethanenitrile + 
dichloromethane + tetrahydrofuran at $298.15 \mathrm{~K}$ is determinate by using Toop model [10], Hillert model [11], Kohler model [12], Muggianu model [13] and Chou model [14, 15]. The geometric models have been used in quaternary system based on the binary information. Multicomponent system properties can be represented as a mixture of all binary system properties. For different selections of binary systems can be used symmetric (Kohler and Muggianu) and asymmetric (Toop and Hillert) models. The current models have unsuitable assumed that the selected binary system is independent of multicomponent system itself. That is causes inherent defects of both and asymmetric models. In order to overcome of this problem was proposed General Solution Model (GSM) by Chou. GSM can overcome the defects of a symmetric and asymmetric model through the introduction of a parameter "similarity coefficient". If two of the three components are similar, the new geometric model can be converted to a binary model. However, conventional geometric models do not do this. Thus, GSM has been successfully applied by many researchers for industrial topics including thermophysical and thermochemical property calculations [16-22]. In this study, we are reformulated Chou's model in terms of the Redlich-Kister (R-K) polynomial [23], which will give an accurate result and simplify the quaternary property calculations. The excess molar volume was calculated from GSM. The results are also compared with experimental data [24] and traditional models, such as Toop, Hillert, Kohler and Muggianu model.

\section{Calculation Models}

Redlich-Kister polynomials [23] can express the excess molar volume binary multicomponent system sub-systems as follows:

$$
V^{e x}=x_{i} x_{j} \sum_{k=0}^{n} L_{i j}^{k}\left(x_{i}-x_{j}\right)^{k}
$$

The parameters of Redlich-Kister for the binary system $i-j$, which is independent of the variable, are represented by $L_{i j}^{k}$. xi and $\mathrm{xj}$, respectively, are the mole fractions of the components $i$ and $j$ in the binary scheme $i-j$. Calculation of excess molar volumes for the quaternary system have been done using different prediction methods, such as Toop [10], Hillert [11], Kohler [12], and Muggianu [13] at 298.15 K. The fundamental equations of these methods of prediction for the quaternary structure, the following are given:

\section{Toop model:}

$$
\begin{aligned}
V^{e x}= & \frac{x_{2}}{1-x_{1}} V_{12}^{e x}\left(x_{1} ; 1-x_{1}\right)+\frac{x_{3}}{1-x_{1}} V_{13}^{e x}\left(x_{1} ; 1-x_{1}\right)+\frac{x_{4}}{1-x_{1}} V_{14}^{e x}\left(x_{1} ; 1-x_{1}\right) \\
& +\left(x_{2}+x_{3}\right)^{2} V_{23}^{e x}\left(\frac{x_{2}}{x_{2}+x_{3}} ; \frac{x_{3}}{x_{2}+x_{3}}\right)+\left(x_{2}+x_{4}\right)^{2} V_{24}^{e x}\left(\frac{x_{2}}{x_{2}+x_{4}} ; \frac{x_{4}}{x_{2}+x_{4}}\right) \\
& +\left(x_{3}+x_{4}\right)^{2} V_{34}^{e x}\left(\frac{x_{3}}{x_{3}+x_{4}} ; \frac{x_{4}}{x_{3}+x_{4}}\right)
\end{aligned}
$$

\section{Hillert model:}

$$
\begin{aligned}
& V^{e x}=\frac{x_{2}}{1-x_{1}} V_{12}^{e x}\left(x_{1} ; 1-x_{1}\right)+\frac{x_{3}}{1-x_{1}} V_{13}^{e x}\left(x_{1} ; 1-x_{1}\right)+\frac{x_{4}}{1-x_{1}} V_{14}^{e x}\left(x_{1} ; 1-x_{1}\right) \\
& +\frac{x_{2} x_{3}}{v_{23} v_{32}} V_{23}^{e x}\left(v_{23} ; v_{32}\right)+\frac{x_{2} x_{4}}{v_{24} v_{42}} V_{24}^{e x}\left(v_{24} ; v_{42}\right)+\frac{x_{3} x_{4}}{v_{34} v_{43}} V_{34}^{e x}\left(v_{34} ; v_{43}\right)
\end{aligned}
$$


where is: $v_{i j}=\frac{1+x_{i}-x_{j}}{2}$

\section{Kohler model:}

$$
\begin{aligned}
& V^{e x}=\left(x_{1}+x_{2}\right)^{2} V_{12}^{e x}\left(\frac{x_{1}}{x_{1}+x_{2}} ; \frac{x_{2}}{x_{1}+x_{2}}\right)+\left(x_{1}+x_{3}\right)^{2} V_{13}^{e x}\left(\frac{x_{1}}{x_{1}+x_{3}} ; \frac{x_{3}}{x_{1}+x_{3}}\right) \\
& +\left(x_{1}+x_{4}\right)^{2} V_{14}^{e x}\left(\frac{x_{1}}{x_{1}+x_{4}} ; \frac{x_{4}}{x_{1}+x_{4}}\right)+\left(x_{2}+x_{3}\right)^{2} V_{23}^{e x}\left(\frac{x_{2}}{x_{2}+x_{3}} ; \frac{x_{3}}{x_{2}+x_{3}}\right) \\
& +\left(x_{2}+x_{4}\right)^{2} V_{24}^{e x}\left(\frac{x_{2}}{x_{2}+x_{4}} ; \frac{x_{4}}{x_{2}+x_{4}}\right)+\left(x_{3}+x_{4}\right)^{2} V_{34}^{e x}\left(\frac{x_{3}}{x_{3}+x_{4}} ; \frac{x_{4}}{x_{3}+x_{4}}\right)
\end{aligned}
$$

\section{Muggianu model:}

$$
\begin{aligned}
& \frac{V^{e x}}{\left(1+x_{1}-x_{2}\right)\left(1+x_{2}-x_{1}\right)} V_{12}^{e x}\left(\frac{1+x_{1}-x_{2}}{2} ; \frac{1+x_{2}-x_{1}}{2}\right)+\frac{4 x_{1} x_{3}}{\left(1+x_{1}-x_{3}\right)\left(1+x_{3}-x_{1}\right)} V_{13}^{e x}\left(\frac{1+x_{1}-x_{3}}{2} ; \frac{1+x_{3}-x_{1}}{2}\right)= \\
& +\frac{4 x_{1} x_{4}}{\left(1+x_{1}-x_{4}\right)\left(1+x_{4}-x_{1}\right)} V_{14}^{e x}\left(\frac{1+x_{1}-x_{4}}{2} ; \frac{1+x_{4}-x_{1}}{2}\right)+ \\
& \frac{4 x_{2} x_{3}}{\left(1+x_{2}-x_{3}\right)\left(1+x_{3}-x_{2}\right)} V_{13}^{e x}\left(\frac{1+x_{2}-x_{3}}{2} ; \frac{1+x_{3}-x_{2}}{2}\right) \\
& +\frac{4 x_{2} x_{4}}{\left(1+x_{2}-x_{4}\right)\left(1+x_{4}-x_{2}\right)} V_{24}^{e x}\left(\frac{1+x_{2}-x_{4}}{2} ; \frac{1+x_{4}-x_{2}}{2}\right)+ \\
& \frac{4 x_{3} x_{4}}{\left(1+x_{3}-x_{4}\right)\left(1+x_{4}-x_{3}\right)} V_{34}^{e x}\left(\frac{1+x_{3}-x_{4}}{2} ; \frac{1+x_{4}-x_{3}}{2}\right)
\end{aligned}
$$

In all equations $V^{e x}$ correspond to the excess molar volume for quaternary system, although $x_{1}, x_{2}, x_{3}$ and $x_{4}$ in the evaluated method correspond to the mole fraction of the components.

Basic theoretical explanations are given for the general solution model [14]:

$$
V^{e x}=\sum_{i, j=1}^{n}{ }_{i \neq j} W_{i j} V_{i j}^{e x}
$$

The molar volume property for an $i j$ binary system is $V_{i j}^{e x}$, and the probability weight of the $i j$ binary is $W_{i j}$. It is possible to express the probability weight of the IJ binary system as follows:

$$
W_{i j}=\frac{x_{i} x_{j}}{X_{i(i j)} X_{j(i j)}},\left[\begin{array}{c}
i, j=1 \text { to } 4 \\
i \neq j
\end{array}\right]
$$

in which the quaternary compositions are represented by $x_{i}$ and $x_{j}$, and $X_{i(i j)}$ and $X_{j(i j)}$ represent the chosen binary compositions that are different for different types of geometric models. When extending the excess molar volume to a quaternary scheme, it can be expressed as:

$$
V^{e x}=W_{12} V_{12}^{e x}+W_{13} V_{13}^{e x}+W_{14} V_{14}^{e x}+W_{23} V_{23}^{e x}+W_{24} V_{24}^{e x}+W_{34} V_{34}^{e x}
$$

$X_{i(i j)}$ and $X_{j(i j)}$ in Eq.(7) the following can be determined in terms of: 


$$
\begin{array}{ll}
X_{1(12)}=x_{1}+x_{3} \cdot \xi_{1(12)}^{(3)}+x_{4} \cdot \xi_{1(12)}^{(4)} ; & X_{1(13)}=x_{1}+x_{2} \cdot \xi_{1(13)}^{(2)}+x_{4} \cdot \xi_{1(13)}^{(4)} \\
X_{1(14)}=x_{1}+x_{2} \cdot \xi_{1(14)}^{(2)}+x_{3} \cdot \xi_{1(14)}^{(3)} ; & X_{2(23)}=x_{2}+x_{1} \cdot \xi_{2(23)}^{(1)}+x_{4} \cdot \xi_{2(23)}^{(4)} \\
X_{2(24)}=x_{2}+x_{1} \cdot \xi_{2(24)}^{(1)}+x_{3} \cdot \xi_{2(24)}^{(3)} ; & X_{3(34)}=x_{3}+x_{1} \cdot \xi_{3(34)}^{(1)}+x_{2} \cdot \xi_{3(34)}^{(2)}
\end{array}
$$

In Eq. (9), $\xi$ is the similarity coefficient which is defined as:

$$
\xi_{i(i j)}^{(k)}=\frac{\eta(i j, i k)}{\eta(i j, i k)+\eta(j i, j k)}
$$

Here $\eta(i j, i k)$ is called the "deviation sum of squares" and can be calculated as follows:

$$
\eta(i j, i k)=\int_{0}^{1}\left(V_{i j}^{e x}-V_{j k}^{e x}\right)^{2} d X_{i}
$$

Within Eq. (11), assessing the integration makes the measurement a little awkward. If the relations between the coefficient of similarity and the Redlich-Kister polynomial parameters are known, the algebraic equation can be carried out. A general relationship that enables us to go to any quaternary structure has recently been derived [16]:

$$
\begin{aligned}
& \eta(i j, i k)=\sum_{l=0}^{n} \frac{1}{2(2 l+1)(2 l+3)(2 l+5)}\left(L_{i j}^{l}-L_{i k}^{l}\right)^{2} \\
& +\sum_{l=0}^{n} \sum_{m>l}^{n} \frac{1}{(l+m+1)(l+m+3)(l+m+5)} \times\left(L_{i j}^{l}-L_{i k}^{l}\right)\left(L_{i j}^{m}-L_{i k}^{m}\right)
\end{aligned}
$$

Substituting Eq. (12) into Eq. (10), it is possible to define coefficients of similarity. If $n$ Eqs. (11-12) is equal to 4, and then it is possible to express "deviation sum of squares" We should write for the $\eta(12,13)$ as follows:

$$
\begin{aligned}
& \eta(12,13)=\frac{1}{30}\left(L_{12}^{0}-L_{13}^{0}\right)^{2}+\frac{1}{210}\left(L_{12}^{1}-L_{13}^{1}\right)^{2}+\frac{1}{630}+\frac{1}{1386}\left(L_{12}^{3}-L_{13}^{3}\right)^{2} \\
& \quad+\frac{1}{2574}\left(L_{12}^{4}-L_{13}^{4}\right)^{2}+\frac{1}{105}\left(L_{12}^{0}-L_{13}^{0}\right)\left(L_{12}^{2}-L_{13}^{2}\right)+\frac{1}{315}\left(L_{12}^{0}-L_{13}^{0}\right)\left(L_{12}^{4}-L_{13}^{4}\right) \\
& \quad+\frac{1}{315}\left(L_{12}^{1}-L_{13}^{1}\right)\left(L_{12}^{3}-L_{13}^{3}\right)+\frac{1}{693}\left(L_{12}^{2}-L_{13}^{2}\right)\left(L_{12}^{4}-L_{13}^{4}\right)
\end{aligned}
$$

Similar $\eta(i j, i k)$ values are also calculated from Eq. (12).

\section{Results and Discussions}

The excess molar volume on mixture systems is one of the most interesting properties of mixing functions since exploring the behavior of liquid systems is a good thermodynamic method. It is also known that a sensitive indicator to accuracy of liquid mixture theories. The positive excess molar volume indicates volume expansion on mixing as seen a maximum at equicomposition $=0.5$ in the binary $\mathrm{HE}(1)+\mathrm{EN}(2)$ and $\mathrm{HE}(1)+\mathrm{DCM}(3)$ and thus repulsive interaction of mixing alloys or weaker interactions than the interactions of the pure components. The negative excess amount, on the other hand, indicates stronger mixed molecular interactions as seen negative deviations from the linear law and for example minimums at equicomposition $=0.5$ in the binary $\mathrm{EN}(2)+\mathrm{DCM}(3)$ and $\mathrm{EN}(2)+\mathrm{THF}(4)$ than individual molecules before mixing. Therefore, these results signify that the interaction between $\operatorname{EN}(2)$ or THF(4) becomes relatively attractive at the mixture forming composition. Moreover, as shown in Figure 
1 the excess molar volumes of the alloy $\mathrm{HE}(1)+\mathrm{THF}(4)$ and $\operatorname{DCM}(3)+\mathrm{THF}(4)$ are almost zero at $298.15 \mathrm{~K}$ over the entire spectrum of concentration. This situation suggests that the liquid these mixtures can be treated as an ideal mixture and are indicative of an ideal mixture at $298.15 \mathrm{~K}$.

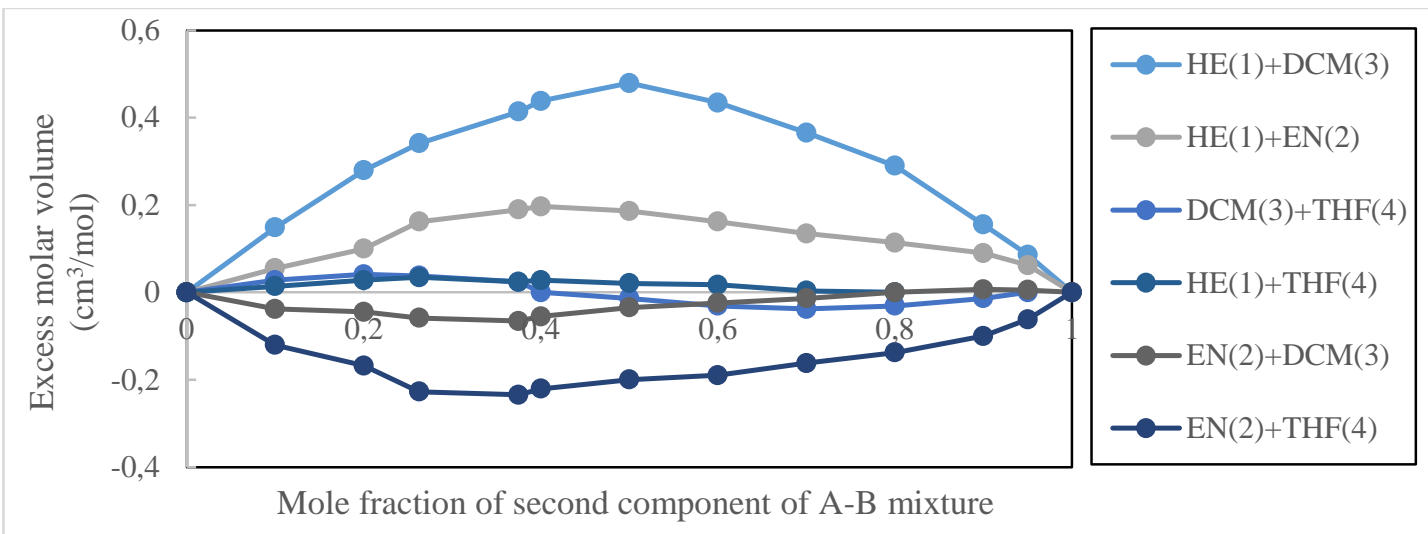

Figure 1. For the three binary systems, experimental values of excess molar volume as a function of nhexanol molar fraction: symbols apply to the experimental data while the lines reflect the results of the ternary Hexanol + Ethanenitrile + Dichloromethane + tetrahydrofuran quaternary method determined from the Redlich-Kister-Muggianu formalism.

Table 1. Redlich-Kister parameters for n-hexanol (1) + ethanenitrile (2) + dichloromethane (3) + tetrahydrofuran (4) binary system at $298.15 \mathrm{~K}$.

\begin{tabular}{|l|l|l|l|l|l|}
\hline \multicolumn{1}{|c|}{ System } & \multicolumn{1}{c|}{$L_{i j}^{0}$} & \multicolumn{1}{c|}{$L_{i j}^{1}$} & \multicolumn{1}{c|}{$L_{i j}^{2}$} & \multicolumn{1}{c|}{$L_{i j}^{3}$} & \multicolumn{1}{c|}{$L_{i j}^{4}$} \\
\hline HE(1)+EN(2) & 0.77419 & -0.39025 & 0.15884 & -0.08105 & 0.22976 \\
\hline HE(1)+DCM(3) & 1.93148 & -0.10038 & -0.58252 & 0.30740 & 0.53022 \\
\hline HE(1)+THF(4) & 0.11280 & -0.09130 & 0.00338 & 0.04194 & -0.02595 \\
\hline EN(2)+DCM(3) & -0.13828 & 0.32532 & -0.14651 & 0.00268 & 0.02211 \\
\hline EN(2)+THF(4) & -0.84025 & 0.63122 & -0.74114 & -0.07811 & 0.57113 \\
\hline DCM(3)+THF(4) & 0.05575 & -0.40898 & -0.21286 & 0.04548 & 0.14401 \\
\hline
\end{tabular}

A quaternary system contains six binary system, and the value before using the binary form, all of these binary systems should be understood symmetric and asymmetric models. Excess molar volumes of the quaternary liquid mixtures n-hexanol + ethanenitrile + dichloromethane + tetrahydrofuran have been measured at 298.15 K [24] and [25]. The R-K form polynomial was used to measure all data for six binary systems and the R-K parameter values for the constituent binary systems given in Table 1 [24] were used for the calculation.

The values of excess molar volume in terms of $\mathrm{cm}^{3} \mathrm{~mol}^{-1}$ for different mixtures of four component of quaternary system have been calculated using Toop, Hillert, Kohler, Muggianu and Chou model and Eqs. (1-13). $x_{1}, x_{2}, x_{3}$ and $x_{4}$ in Table 1 represent mole fraction of n-hexanol, ethanenitrile, dichloromethane and tetrahydrofuran, respectively. For comparison, the results of asymmetric model (Toop, Hillert) and symmetric model (Kohler, Muggianu) as well as the experimental data are also included.

In the ternary n-hexanol + ethanenitrile + dichloromethane and quaternary system nhexanol + ethanenitrile + dichloromethane + tetrahydrofuran at $298.15 \mathrm{~K}$, the excess molar volumes of mixing are shown in Figures 2, 3 and Figures 4-7 for comparison, respectively. From the Figures 2 and 3, the molar volume values of the ternary nhexanol + ethanenitrile + dichloromethane for the sections $\mathrm{He} / \mathrm{En}=1.49049$ and 4.089 
show nonlinear dependence strongly at $298.15 \mathrm{~K}$ for all the compositions in the ranges of 0-0.6 and 0.8. In addition, it can be seen from Figures 4-7 that the molar volume values of the quaternary system n-hexanol + ethanenitrile + dichloromethane + tetrahydrofuran at $298.15 \mathrm{~K}$ show also nonlinear dependence strongly in the ranges of the related sections He/En and DCM+THF.

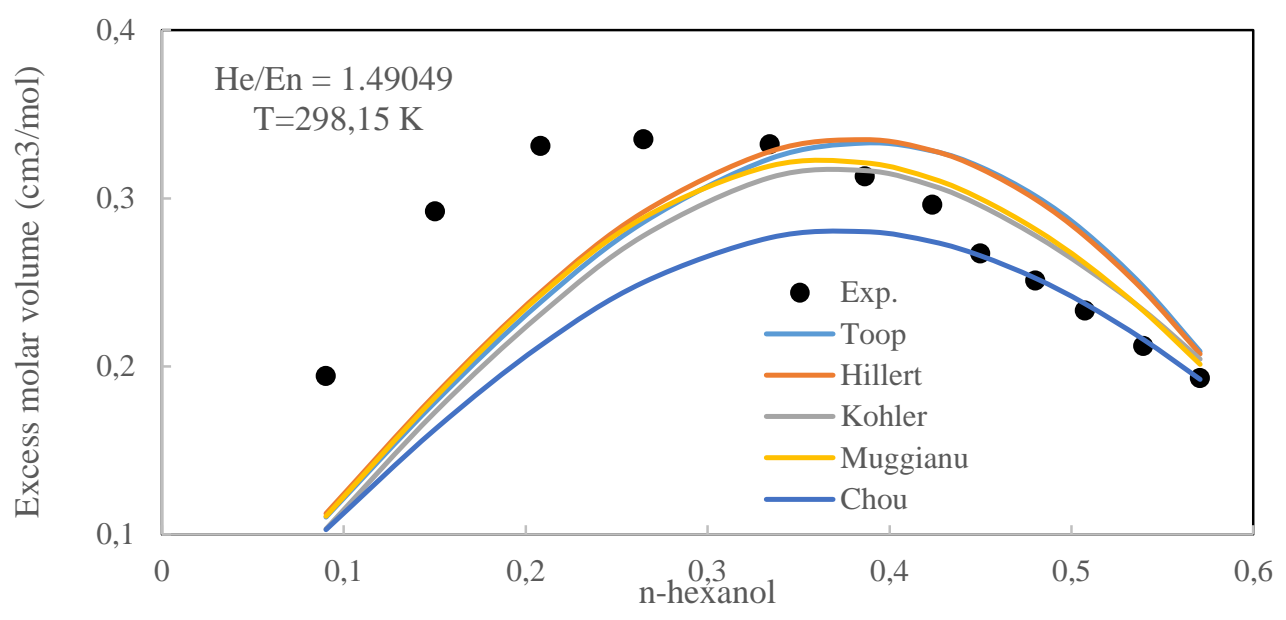

Figure 2. Comparison of the traditional models, Chou model and experimental data associated with the excess molar volume for the section $x_{1} / x_{2}=1.49049$ in the ternary Hexanol + Ethanenitrile + Dichloromethane.

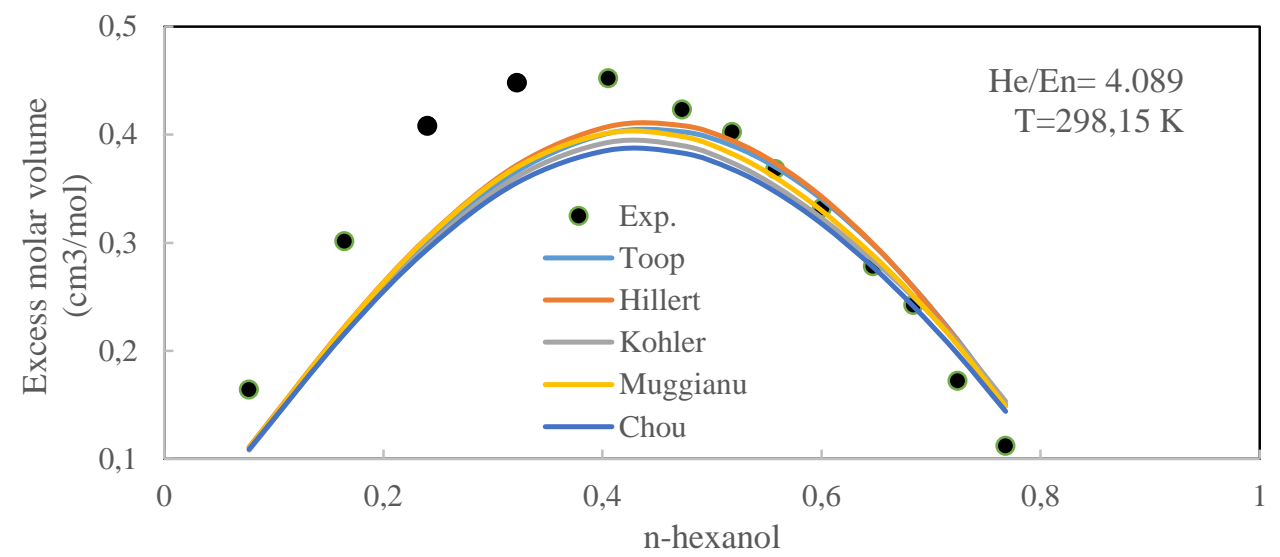

Figure 3. Comparison of the traditional models, Chou model and experimental data associated with the excess molar volume for the section $x_{1} / x_{2}=4.089$ in the ternary Hexanol + Ethanenitrile + Dichloromethane. 


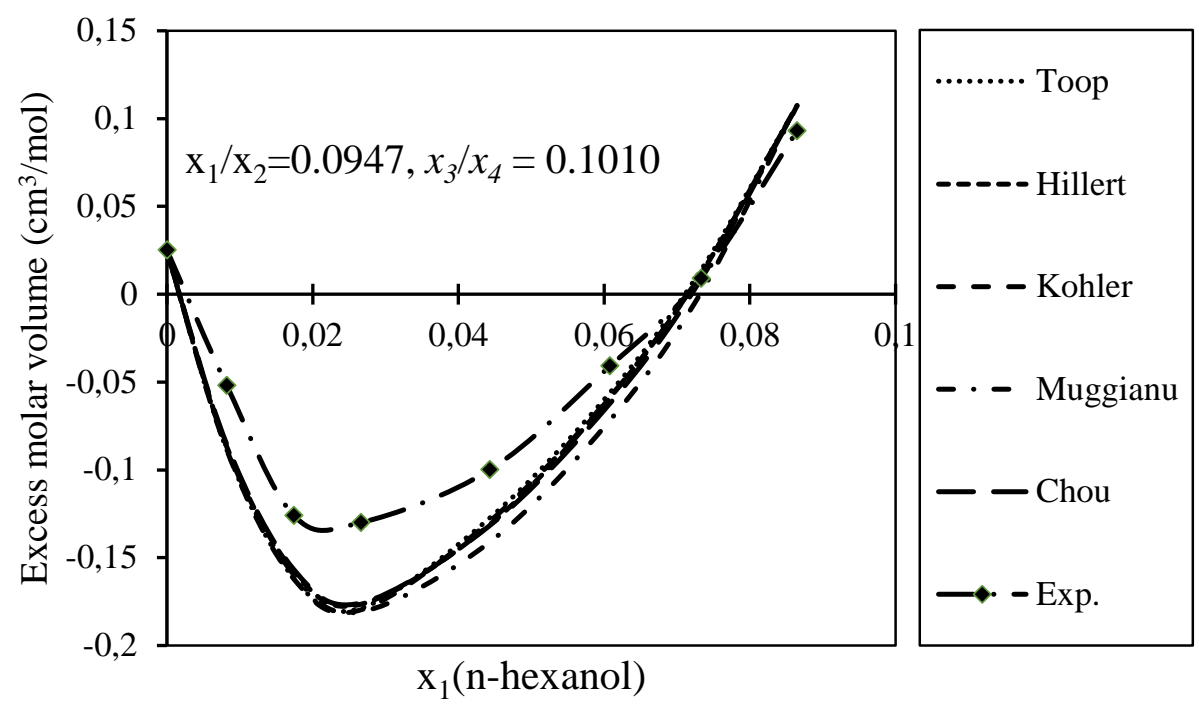

Figure 4. Comparison of the traditional models, Chou model and experimental data of excess molar volume for the section $x_{1} / x_{2}=0.0947 ; x_{3} / x_{4}=0.1010$ in the quaternary Hexanol + Ethanenitrile +

Dichloromethane + tetrahydrofuran quaternary system.

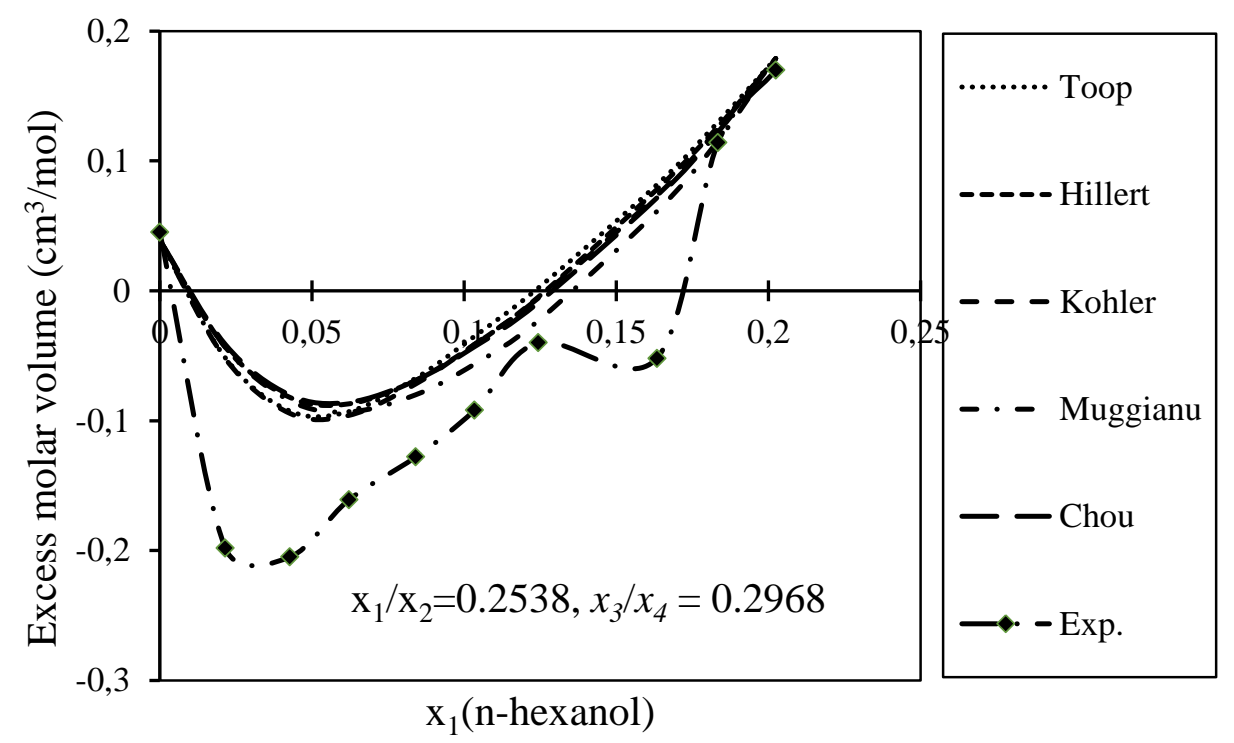

Figure 5. Comparison of the traditional models, Chou model and experimental data of excess molar volume for the section $x_{1} / x_{2}=0.2538 ; x_{3} / x_{4}=0.2968$ in the quaternary Hexanol + Ethanenitrile + Dichloromethane + tetrahydrofuran quaternary system. 


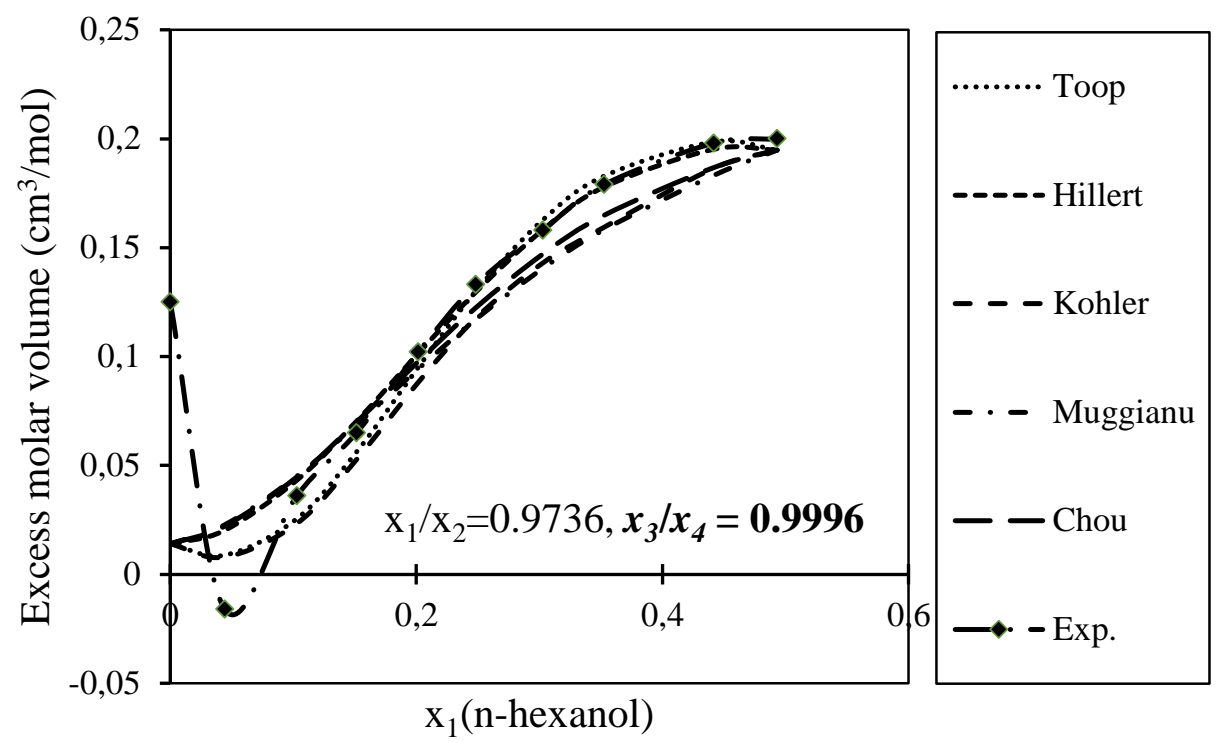

Figure 6. Comparison of the traditional models, Chou model and experimental data of excess molar volume for the section $x_{1} / x_{2}=0.9736 ; x_{3} / x_{4}=0.9996$ in the quaternary Hexanol + Ethanenitrile +

Dichloromethane + tetrahydrofuran quaternary system.

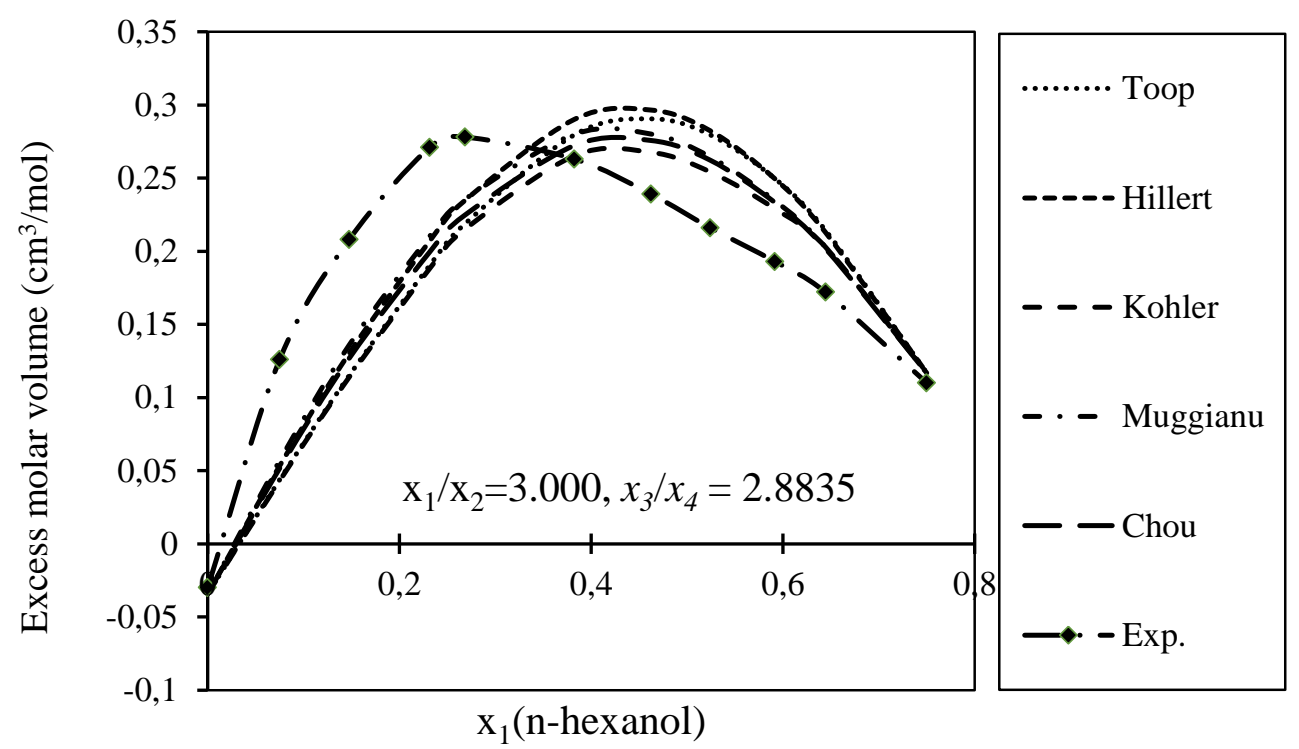

Figure 7. Comparison of the traditional models, Chou model and experimental data of excess molar volume for $x_{1} / x_{2}=3.0000 ; x_{3} / x_{4}=2.8835$ in the quaternary Hexanol + Ethanenitrile + Dichloromethane + tetrahydrofuran quaternary system.

All models treated in the present study lead to a little deviation from the experimental values due to boundary between symmetric and asymmetric models. In order to accurately the deviation between used models and experimental data [24], the mean deviation $(M D)$ analysis was applied to excess molar volumes data:

$$
M D=\frac{1}{n} \sqrt{\sum_{i=1}^{n}\left(V_{\text {exp }, i}^{e x}-V_{c a l, i}^{e x}\right)^{2}}
$$


in which, $n$ the number of counting points, $V_{\text {exp }}^{\text {ex }}$ experimental data results, $V_{c a l}^{e x}$ calculated values for excess molar volume. The results of $M D$ analysis are presented in Table 2.

Table 2. In the current study for Hexanol + Ethanenitrile + Dichloromethane + Tetrahydrofuran quaternary method, the measured mean deviation corresponds to the experimental results for each model.

Sections

Mean Deviation Values (MD)

\begin{tabular}{clllllll}
$\begin{array}{l}\text { He/En } \\
\text { with Exp. }\end{array}$ & Dcm/Thf & Toop & Hillert & Kohler & Muggianu & Chou & Model Agreeing \\
\hline 0.0947 & 0.1010 & 0.00983 & 0.00960 & 0.01008 & 0.01109 & 0.00954 & Chou \\
3.0000 & 2.8835 & 0.0256 & 0.0263 & 0.0246 & 0.02450 & 0.02610 & Muggianu \\
0.9736 & 0.9996 & 0.01151 & 0.01173 & 0.01200 & 0.01233 & 0.01203 & Toop \\
0.2538 & 0.2968 & 0.01759 & 0.01592 & 0.0160 & 0.01365 & 0.01472 & Muggianu \\
1.49049 & - & 0.01694 & 0.01618 & 0.01647 & 0.01513 & 0.01883 & Muggianu \\
4.089 & - & 0.01429 & 0.01475 & 0.01519 & 0.01382 & 0.01563 & Muggianu \\
\hline
\end{tabular}

It can be seen results of the $M D$ analysis in Table 2 that a good agreement has been demonstrated between the predictions of the models and the experimental data. Moreover, Chou's model also agrees with the experimental results while a good agreement is obtained mutually one another the models treated in the ternary and quaternary mixtures. When a comparison was done with experimental results for the section, $\mathrm{He} / \mathrm{En}=0.0947, \mathrm{Dcm} / \mathrm{Thf}=0.1010$ in the quaternary system, it is seen that a reasonable agreement with Chou's model. Chou's model appears to be valid and could be successfully applied for the prediction of these types of ternary systems. It can be seen for other quaternary systems that a reasonable agreement with Toop and Muggianu models for the sections He/En=0.9736, Dcm/Thf $=0.9996, \mathrm{He} / \mathrm{En} 3.0000, \mathrm{Dcm} / \mathrm{Thf}$ $=2.8835$ and $\mathrm{He} / \mathrm{En}=0.2538, \mathrm{Dcm} / \mathrm{Thf}=0.2968$, respectively. It is observed from Table 2 that there are the agreements with the experimental results for both sections in the quaternary mixtures. Muggianu models also appear to be valid and could be successfully applied for the prediction of these types of ternary systems.

\section{Conclusion}

In this work, the ternary mixtures are estimated to calculate the excess molar volumes of the mixtures n-hexanol + ethanenitrile + dichloromethane and quaternary system nhexanol + ethanenitrile + dichloromethane + tetrahydrofuran at 298.15 K associated with ternary and quaternary systems, the Chou's model was extended to ternary and quaternary systems using binary mixture properties. According to the ternary systems, the only difference was including the extra binary terms in both the excess properties. The benefit of the current model is that human intervention in defining the asymmetrical variable is not necessary. In addition, one of the important contributions to Chou's model that the high order framework can be easily expanded, such as quaternary system readily the inclusion of the comparable extra words in the excess molar volume formulae associated with ternary system. Moreover, the analysis of mean deviation has been carried out and in line with this analysis: the results obtained have displayed reliability of the Chou's model for the section $\mathrm{He} / \mathrm{En}=0.0947, \mathrm{Dcm} / \mathrm{Thf}=0.1010$ in the quaternary system, except for the other sections. It is concluded that Muggianu model 
for ternary mixture system appears to be valid and could be successfully applied for the prediction of these types of ternary systems for the two sections, $\mathrm{He} / \mathrm{En}=3.0000$, $\mathrm{Dcm} / \mathrm{Thf}=2.8835$ and He/En $=0.2538, \mathrm{Dcm} / \mathrm{Thf}=0.2968$.

\section{Author Statement}

Hüseyin Arslan: Investigation, Original Draft Writing, Review and Editing., Investigation, Review and Editing, Supervision, Observation, Advice.

\section{Conflict of Interest}

As an only one author of this study, we declare that we do not have any conflict of interest statement.

\section{Ethics Committee Approval and Informed Consent}

As an authors of this study, I declare that I do not have any ethics committee approval and/or informed consent statement.

\section{References}

[1] S. Fürtauer, E. Tserenjav, A. Yakymovych, and H. Flandorfer, "Calorimetric studies of Cu- $\mathrm{Li}, \mathrm{Li}-$ Sn, and Cu-Li-Sn," J. Chem. Tthermodyn., 61, 105-116, 2013.

[2] X. Yang, H. Yang, D. Tao, and D. Liu, "A modified Hoch-Arpshofen model for the calculation of enthalpies of formation of multicomponent liquid alloys," Fluid Phase Equilib., 363, 207-212, 2014.

[3] M. Behroozi and H. Zarei, "Volumetric properties of binary mixtures of tributylamine with benzene derivatives and comparison with ERAS model results at temperatures from (293.15 to 333.15) K," $J$. Chem.Thermodyn., 47, 267-287, 2012.

[4] H. Jiang, J. Wang, F. Zhao, G. Qi, and Y. Hu, "Volumetric and surface properties of pure ionic liquid n-octyl-pyridinium nitrate and its binary mixture with alcohol," J.Chem.Tthermodyn., 47, 203208, 2012.

[5] J. S. Matos, J. L. Trenzado, E. González, and R. Alcalde, "Volumetric properties and viscosities of the methyl butanoate+ n-heptane+ n-octane ternary system and its binary constituents in the temperature range from 283.15 to 313.15 K," Fluid Phase Equilib., 186(1-2), 207-234, 2001.

[6] Y. Liu, X. Lv, C. Bai, P. Lai, and J. Wang, "Viscosity evaluation of Fe-Ni-Co ternary alloy from the measured binary systems," J. Ind. Eng. Chem., 30, 106-111, 2015.

[7] M. Schick, J. Brillo, I. Egry, and B. Hallstedt, "Viscosity of Al-Cu liquid alloys: measurement and thermodynamic description," J. Mater. Sci. 47(23), 8145-8152, 2012.

[8] S. K. Begum, R. J. Clarke, M. S. Ahmed, S. Begum, and M. A. Saleh, "Volumetric, viscosimetric and surface properties of aqueous solutions of triethylene glycol, tetraethylene glycol, and tetraethylene glycol dimethyl ether," J. Mol. Liq., 177, 11-18, 2013.

[9] G.-H. Zhang and K.-C. Chou, "Estimating the excess molar volume using the new generation geometric mode,." Fluid Phase Equilib., 286(1), 28-32, 2009.

[10] G. Toop, "Predicting ternary activities using binary data," Trans. TMS-AIME, 223, 850-855, 1965.

[11] M. Hillert, "Empirical methods of predicting and representing thermodynamic properties of ternary solution phases," Calphad, 4(1), 1-12, 1980.

[12] F. Kohler, "Zur Berechnung der thermodynamischen Daten eines ternären Systems aus den zugehörigen binären Systemen," Monatsh Chem. Verw.Teile. Anderer., 91(4), 738-740, 1960.

[13] Y. M. Muggianu, M. Gambino, and J. Bros, "Enthalpies of formation of liquid alloys bismuthgallium-tin at $723 \mathrm{k}$-choice of an analytical representation of integral and partial thermodynamic functions of mixing for this ternary-system," J. chim. Phys. Phys.-Chim. Biol., 72(1), 83-88, 1975.

[14] K.-C. Chou, "A general solution model for predicting ternary thermodynamic properties," Calphad, 19(3), 315-325, 1995

[15] K.-C. Chou and S.-K. Wei, "A new generation solution model for predicting thermodynamic properties of a multicomponent system from binaries," Metall. Mater. Trans B, 28(3), 439-445, 1997.

[16] G.-H. Zhang, and K.-C. Chou, "General formalism for new generation geometrical model: application to the thermodynamics of liquid mixture,." J. Solution Chem., 39(8), 1200-1212, 2010. 
[17] I. Katayama, Y. Fukuda, Y. Hattori, and T. Maruyama, "Measurement of activity of gallium in liquid Ga-Sb-Sn alloys by EMF method with zirconia as solid electrolyte," Thermochim. Acta, 314(1-2), 175-181, 1998.

[18] L. Wang, K.-C. Chou, and S. Seetharaman, "A comparison of traditional geometrical models and mass triangle model in calculating the surface tensions of ternary sulphide melt,." Calphad, 32(1), 49-55, 2008.

[19] L. Prasad and A. Mikula, "Surface segregation and surface tension in Al-Sn-Zn liquid alloys," Physica B Condens., 373(1), 142-149, 2006.

[20] L. Yan, S. Zheng, G. Ding, G. Xu, and Z. Qiao, "Surface tension calculation of the Sn-Ga-In ternary alloy," Calphad, 31(1), 112-119, 2007.

[21] C. Costa, S. Delsante, G. Borzone, D. Zivkovic, and R. Novakovic, "Thermodynamic and surface properties of liquid Co-Cr-Ni alloys," J. Chem. Thermodyn., 69, 73-84, 2014.

[22] A. Dogan and H. Arslan, "Comparative thermodynamic prediction of integral properties of six component, quaternary, and ternary systems," Metall. Mater. Trans.A, 46(8), 3753-3760, 2015.

[23] O. Redlich and A. Kister, "Algebraic representation of thermodynamic properties and the classification of solution," Ind. Eng. Chem. Res., 40(2), 345-348, 1948.

[24] S. H. Canzonieri, M. A. Postigo, J.A. Salas, and M. Katz, "Excess molar volumes excess viscosities and refractive indices of quaternary liquid mixtures at $298.15 \mathrm{~K}$," Anales-Asociacion Quimica Argentina, 90(1/3), 31-48, 2002.

[25] S. Aznarez, M. A. Postigo, G. C. Pedrosa, I. L. Acevedo, and M. Katz, "Densities, refractive indexes, and excess properties of mixing of the n-hexanol+ ethanenitrile+ dichloromethane ternary system at 25 C," J Solution Chem., 27(10), 949-964, 1998. 